\title{
Nanotechnology and Mesenchymal Stem Cells for Regenerative Medicine
}

\author{
Paz de la Torre and Ana I Flores* \\ General Regenerative Medicine Group, Hospital Research Institute, Spain
}

Submission: February 13, 2017; Published: March 06, 2017

*Corresponding author: Ana I Flores, Ph.D. Research Center, Regenerative Medicine Group, Spain, Tel: +34 913908762; Fax: +34 913908544;

E-mail: anaisabel.flores@salud.madrid.org; aflores@h12o.es

\begin{abstract}
Nanotechnology has emerged as an area with great potential for the treatment of several human diseases. The use of nanobiomaterials, drug delivery systems, gene therapies, diagnostic and surgical robotic tools, nanobiomedical devices, amongst others, is called nanomedicine or bio-nanotechnology in healthcare. It has been shown that stem cells have an important reparative potential for restoring the function of injured tissues and organs. Nanotechnology and stem cell research are two interesting fields that are gradually becoming a newly merged field of modern research. This novel field, stem cell nanotechnology, has generated high interest in human healthcare because it could result in significant contributions in regenerative medicine and tissue engineering. Mesenchymal stem/stromal cells or mesenchymal stromal cells (MSCs) are a special type of stem cell with some interesting properties, such as easy isolation, high rate of proliferation in culture and their differentiation capacity into several cell lines. Moreover, it has been shown that MSCs contribute to tissue repair due to their tropism for injury sites. It has been proposed that MSCs can be useful as cellular vehicles for medications. Human MSCs have been isolated from different tissues such as bone marrow, adipose tissue, cord blood, Wharton's jelly, dental pulp and placenta. The new field of MSCs/nanobiomaterials could give challenging advances in tissue regeneration in the next decade.
\end{abstract}

Keywords: Nanotechnology; Nanomaterials; Scaffolds; Mesenchymal Stem Cells; Regenerative Medicine; Tissue Engineering

\section{Introduction}

Nanotechnology is a highly interdisciplinary field which has seen rapid development in recent years in the treatment of injured organs using tissue engineering. Stem cell and nanotechnology are two fields that are progressively becoming a new combined field, referred to as stem cell nanotechnology, which designate the uses of nanotechnology in stem cell research and development. Stem cell nanotechnology has generated high interest in biomedicine and is currently being used for treatment, healing, and regeneration of cells and tissues $[1,2]$. For the efficiency of stem cell transplantation on tissue regeneration it is very important to provide biocompatible scaffolds that form a temporary 3D matrix. These biomaterials will support cell-biomaterial communications, cell adhesion, cell proliferation, and finally, tissue repair. The nanomaterials developed over the past decade for stem cell engineering are focused on the potential applications of these nanomaterials in tissue regeneration, stem cell isolation, and drug/gene delivery [3]. However, the effects of nanomaterials on stem cells need more extensive evaluation [4].
Stem cells have tremendous potential in medicine because of their ability to self-renew and differentiate into many cell types. There is a special type of stem cell, called mesenchymal stem/ stromal cell (MSC) that has the ability to migrate throughout the body and home in on where the injury is located in order to repair the damage. MSCs have the potential to evolve into a whole range of different tissue types, i.e., they are multipotent cells. MSCs also have paracrine effects, that is, the cells secrete some soluble factors that are responsible for their therapeutic effects. Alternatively, MSCs can also serve as cellular vehicles and/or delivery systems for medications in order to increase their efficacy and decrease their side effects. They are isolated from several tissues, such as, bone marrow, adipose tissue, umbilical cord, and placenta. Nanotechnology in MSC research is focused on three main areas: labeling and/or tracking of the cells, delivery of different molecules and use of scaffolds. Nanoparticles allow labeling the cells and tracking them once injected for better understanding of the mechanisms involved after MSCs transplantation in vivo, such as, proliferation, 
differentiation, migration and grafting within the host tissue $[5,6]$.

In addition, nanoparticles can be used as carriers of DNA, siRNA, and drugs that can be introduced into MSCs for delivery to damaged organs $[6,7]$. One of the major problems found in MSC transplantation is the deficient engraftment of stem cells onto the injured tissues, as well as, their survival for the time needed to repair the damage. Biomaterial scaffolds mimicking the extracellular matrix environment will overcome these problems and improve MSCs transplant in some pathologies [8]. Here, we will review some of the strategies used combining nanotechnology and MSCs in several diseases.

\section{Bone regeneration}

The treatment of fracture nonunion and bone loss related to different diseases still remains a major challenge to the field of musculoskeletal injury. Biomaterials for bone regeneration should be biocompatible, with osteoinductive, osteoconductive properties and mechanically compatible with native bone. Different types of scaffold materials, such as, metals, ceramics, polymers, collagen, calcium phosphate biomaterials, functionalized silk films have been used with MSCs in bone tissue engineering $[9,10]$.

\section{Cardiac Regeneration}

Heart damage is one of the most challenging diseases to deal with because cardiac myocytes cannot regenerate themselves after injury. Several studies have suggested that MSCs could differentiate into cardiomyocytes, both in vitro and in vivo Stem cells included in 3D micro- or nanoscaled structures could be a promising way to treat cardiac patients helping to overcome myocardial infarction and heart failure [11,12].

\section{Neural diseases}

Neurological disorders are complex and represent a challenging clinical problem. MSCs are able to differentiate in vitro into several neural lineages, including astrocytes, oligodendrocytes and neurons, while reduced engraftment and differentiation were found when transplanted in vivo. The use of nanofibres and nanoscaffolds together with MSCs seems to facilitate nerve regeneration more efficiently than transplantation of stem cells alone [13]. Also, the chemical composition of scaffolds and their pore size has important effects on the differentiation capacity of MSC to in nerve cells [14].

\section{Cancer treatment}

MSCs have been shown to migrate towards inflammatory sites and they are also able to migrate towards and home in on tumors [15]. MSCs secrete growth factors, cytokines, and chemokines, which may can inhibit or, in some cases promote, the growth of tumor cells in vitro and in vivo[15,16]. In addition, MSCs can be used as cellular vehicles of nanoparticles loaded with anticancer drugs in order to increase the number of nanoparticles into the tumor, reducing the side effects of drugs and enhancing their effect [6].

\section{Pelvic floor disorder}

Pelvic organ prolapse is a female pathology frequently linked to childbirth which triggers a weakening of muscles and ligaments causing urinary problems along with other symptoms. A 3D computer model has been developed which could help to find a treatment for pelvic organ prolapse [17]. This biomechanical model could add to our understanding of the evolution of injuries and why surgery to repair prolapse fails. This technology in combination with MSCs containing functionalized nanoparticles could help in the study as to whether stem cells induce tissue repair and, if so, how it takes place [6]. The combination of nanofibrous pads or polymer scaffolds and MSCs could be also good strategies to improve the outcomes of surgical interventions $[18,19]$.

\section{Conclusion}

The combination of nanotechnology and MSC research is a relevant and highly promising field that could provide significant contributions to improving healthcare. However, the use of MSCs together with nanoengineered surfaces and structures for tissue regeneration is still in its early stages. Therefore, intensive research into MSC-nanomaterials interactions and their effects under in vivo and in vitro conditions is still required to apply these novel technologies to medical treatments. For this, the combined knowledge and expertise of engineers, biologists, chemists, and clinicians is essential.

\section{Acknowledgement}

The authors are very grateful to Ian Ure for the English Grammar revision This work was supported by Comunidad de Madrid (MULTIMAT-CHALLENGE, Ref: S2013/MIT-2862) and projects PI 13/00045 and PI15/01803, from the Instituto de Salud Carlos III (Ministry of Economy, Industry and Competitiveness) and cofunded by the European Regional Development Fund, and approved by the Ethics Committee of our Institution.

\section{References}

1. Hofmann MC (2014) Stem cells and nanomaterials. Adv Exp Med Biol 811: 255-275.

2. Solanki A, Kim JD, Lee KB (2008) Nanotechnology for regenerative medicine: nanomaterials for stem cell imaging. Nanomedicine 3(4): 567-578.

3. Kaur S, Singhal B (2012) When nano meets stem: the impact of nanotechnology in stem cell biology. J Biosci Bioeng, 113(1): 1-4.

4. Kerativitayanan P, JK Carrow, Gaharwar AK (2015) Nanomaterials for Engineering Stem Cell Responses. Adv Healthc Mater 4(11): 16001627.

5. Moraes L, Vasconcelos-dos-Santos A, Santana FC, Godoy MA, Rosadode-Castro PH, et al. (2012) Neuroprotective effects and magnetic resonance imaging of mesenchymal stem cells labeled with SPION in a rat model of Huntington's disease. Stem Cell Res 9(2): 143-155. 
6. Juan L Paris, Paz de la Torre, Miguel Manzanoa, Victoria Cabañasa M Ana I Flores, et al. (2016) Decidua-derived mesenchymal stem cells as carriers of mesoporous silica nanoparticles. In vitro and in vivo evaluation on mammary tumors. Acta Biomaterialia 33: 275-282.

7. Verma S, AJ Domb, Kumar N (2011) Nanomaterials for regenerative medicine. Nanomedicine 6(1): 157-181.

8. Sivaraman B, CA Bashur, Ramamurthi A (2012) Advances in biomimetic regeneration of elastic matrix structures. Drug Deliv Transl Res 2(5): 323-350.

9. Cifuentes SC, Bensiamar F, Gallardo-Moreno AM, Osswald TA, GonzalezCarrasco JL, et al. (2016) Incorporation of Mg particles into PDLLA regulates mesenchymal stem cell and macrophage responses. J Biomed Mater Res A 104(4): 866-878.

10. Kargozar S, Mozafari M, Hashemian SJ, Brouki Milan P, Hamzehlou S, et al. (2016) Osteogenic potential of stem cells-seeded bioactive nanocomposite scaffolds: A comparative study between human mesenchymal stem cells derived from bone, umbilical cord Wharton's jelly, and adipose tissue. J Biomed Mater Res B Appl Biomater.

11. Murtuza B, JW Nichol, Khademhosseini A (2009) Micro- and nanoscale control of the cardiac stem cell niche for tissue fabrication. Tissue Eng Part B Rev 15(4): 443-454.

12. Calin M, D Stan, Simion V (2013) Stem cell regenerative potential combined with nanotechnology and tissue engineering for myocardial regeneration. Curr Stem Cell Res Ther 8(4): 292-303.

13. Oliveira JT, Almeida FM, Biancalana A, Baptista AF, Tomaz MA, et al. (2010) Mesenchymal stem cells in a polycaprolactone conduit enhance median-nerve regeneration, prevent decrease of creatine phosphokinase levels in muscle, and improve functional recovery in mice. Neuroscience 170(4): 1295-1303.

14. Prabhakaran MP, Venugopal JR, Ramakrishna S (2009) Mesenchymal stem cell differentiation to neuronal cells on electrospun nanofibrous substrates for nerve tissue engineering. Biomaterials 30(28): 49965003.

15. Vegh I, Grau M, M Gracia, Grande J, de la Torre P, et al. (2013) Decidua mesenchymal stem cells migrated toward mammary tumors in vitro and in vivo affecting tumor growth and tumor development. Cancer Gene Ther 20(1): 8-16.

16. De Boeck A, Pauwels P, Hensen K, Rummens JL, Westbroek W, et al. (2013) Bone marrow-derived mesenchymal stem cells promote colorectal cancer progression through paracrine neuregulin 1/HER3 signalling. Gut 62(4): 550-560.

17. Luo J, Chen L, Fenner DE, Ashton-Miller JA, DeLancey JO (2015) A multicompartment 3-D finite element model of rectocele and its interaction with cystocele. J Biomech 48(9): 1580-1586.

18. Ge L, Li Q, Jiang J, You X, Liu Z, et al. (2015) Integration of nondegradable polystyrene and degradable gelatin in a core-sheath nanofibrous patch for pelvic reconstruction. Int J Nanomedicine 10: 3193-3201.

19.Xu R, Taskin MB, Rubert M, Seliktar D, Besenbacher F, et al. (2015) hiPS-MSCs differentiation towards fibroblasts on a 3D ECM mimicking scaffold. Sci Rep 5: 8480.

\section{Your next submission with JuniperPublishers} will reach you the below assets

- Quality Editorial service

- Swift Peer Review

- Reprints availability

- E-prints Service

- Manuscript Podcast for convenient understanding

- Global attainment for your research

- Manuscript accessibility in different formats

( Pdf, E-pub, Full Text, Audio)

- Unceasing customer service

Track the below URL for one-step submission https://juniperpublishers.com/submit-manuscript.php 